\title{
Experience of Organizing and Holding All-Russian Olympiads for Schoolchildren on Technology
}

\author{
Khotuntsev Yu. L. \\ Moscow State Teacher Training University, Moscow, Russia
}

\begin{abstract}
To identify and encourage talented pupils in Russian Federation, 21 All-Russian Olympiads for schoolchildren have been annually carried out. Many Russian universities have their own Olympiads, besides these All-Russian Olympiads. This paper aims to describe the objectives and tasks of the All-Russian Olympiads for schoolchildren, show the experience of organizating and holding All-Russia Olympiads, and present the stages and content of the annual All-Russian Olympiad. Each Olympiad consists of four stages: school, municipal, regional, and final. Each stage includes testing of schoolchildren's creative tasks and practical work, and finally, presentation of a creative project. The All-Russian Olympiad for schoolchildren on techology has two nominations: (a) "Technics and Technical Creativity"; and (b) "Culture of Home and Decoration and Applied Arts". Practical activities and practical incarnation of the project play the most important role in programme of "Technology" in Russian schools. In technology education, $70 \%$ of the time is based on practice. Examples of tests, practical works, and some projects in 2014 and 2015 years on the nomination "Technics and Technical Creativity" are given in this paper. Experience from realization of All-Russian Olympiads on technology showed that this as an effective form to identify and encourage talented pupils.

Keywords: technological education, All-Russian Olympiads for schoolchildren, stages, content, tests, creative task, practical work, presentation of a creative project
\end{abstract}

\section{Introduction}

To identify and encourage talented pupils in Russian Federation, 21 All-Russian Olympiads for schoolchildren are annually carried out in the following school subjects: Russian, English, German, French, Astronomy, Geography, Physics, Chemistry, Biology, Art (World Fine Art), Computer Science and Information and Communication Technologies, Mathematics, Literature, History, Social Science, Economy, Ecology, Law, Physical Culture, Health and Safety, and Technology.

Each Olympiad has four stages: (a) school (carried out no later than October 15 every academic year); (b) municipal (carried out before December 25); (c) regional (carried out before February 25); and (d) final (carried out before April 30). The regional stage of every Olympiad is carried out in two days. The final stage of the Olympiad takes six days.

\section{Objectives and Tasks of All-Russian Olympiads}

All-Russian Olympiads for schoolchildren on technology have been carried out since 2000 (Khotuntsev,

Khotuntsev Yu. L., D.Sc., professor, Department of Technology and Professional Training, Moscow State Teacher Training University. 
2005; 2006). While tens of thousands of schoolchildren participate in the school stage of the Olympiad, only about 200 schoolchildren of 9-11 grades participate in the final stage (in Russia, school education lasts 11 years).

The main objectives of the All-Russian Olympiad for schoolchildren on technology are:

1. To identify and develop creative abilities and interest in scientific (research) activity;

2. To promote scientific knowledge;

3. To promote school technological education and growth of its level;

4. To bring closer contents and methods of material and information technologies in education;

5. To promote method of projects as the main means to disclose creative potential in children;

6. To identify and encourage the most talented schoolchildren;

7. To identify and encourage the most creative teachers of technology;

8. To involve schoolchildren in creating concrete and practically important, socially significant projects aimed at development of technical and art creativity.

The tasks of the All-Russian Olympiad on technology are to identify and assess theoretical knowledge of talented schoolchildren in various sections of the subject "Technology", their abilities to use this knowledge, assessment of practical abilities of schoolchildren, and their creative projects.

Table 1

Sections of the Program on "Technology"

1. Definition (content) of technology:

(a) The role of engineering and technology in the development of society;

(b) Technosphere;

(c) Production structure: requirements, resources, technological systems, processes, control, and sale.

2. History of engineering and technology;

3. Machine studies;

4. Material studies: wood, metals, and plastic;

5. Technology of wood processing;

6. Technologies of processing of metals;

7. Laser technologies;

8. Nanotechnologies;

9. Repair and construction works (technology of maintaining house);

10. Art processing of materials;

11. Design;

12. Technical creativity;

13. Electrical equipment and electronics. Ways of generating, transmitting, and applying electric power;

14. Alternative energetic;

15. Information and communication technologies, CNC machines, 3D-printers, "smart" houses, automatic equipment, and robotics.

16. Drafting;

17. Family economy;

18. Business basics;

19. Vocational guidance;

20. Production and environment;

21. Projects.

\section{Methods}

The All-Russian Olympiad for schoolchildren on technology has two nominations: "Technics and Technical Creativity" and "Culture of Home and Decorative and Applied Arts". This Olympiad includes three 
rounds at each stage. The first round is testing schoolchildren in order to assess their knowledge and their abilities to apply this knowledge practically. About half of the tests are given in an open form (without offered answers) to check not only knowledge, but also ability of schoolchildren to formulate their thoughts.

At the school stage, pupils of the 5th grade are given 10 tests; of the 6th grade, 15 tests; of the 7 th grade, 20 tests; and of the 9th, 10th, and 11th grades, 30 tests.

At the municipal stage, 25 tests are given to the 7 th-8th grade pupils, and 35 tests for the 9 th, 10 th, and 11th grade pupils.

Taking into account development of technologies (laser technologies, nanotechnology, robotics, 3D-printers, Computer Numerical Control (CNC) machines, "smart" houses, alternative energy, etc.), relevant questions should be included in the tests. Given this, the tests should include material from the following sections of the curriculum in "Technology" in the category "Technics and Technical Creativity" (see Table 1).

Each correct answer to the test question is given 1 point, wrong or incomplete answer receives 0 point. For 35 tests, the total number of points for the theoretical performance of tasks must not exceed 35 .

As an example, a test for the 9th grade will be provided in Table 2 (Khotuntsev \& Glozman, 2014).

Table 2

An Example Text for the 9th Grade

1. Transformation of a rotary motion to the forward is carried out with the help (Choose the right answer with the sign " +"):

(a) The chain drive; (b) Gear transmission; (c) Rack gear; and (d) Belt drive

2. On what power stations: nuclear, hydroelectric, thermal, wind power, or other is the main part of the electricity used made? What is the main environmental disadvantage of these power plants?

In future, starting with the final stage of the All-Russian Olympiad on technology in 2015, it is better to offer not 35 but 25 tests, with 10 tests to be replaced with the following creative task: to design in general the process of manufacturing products specified in verbal form. Dimensions either can be specified beforehand, or should be chosen. Schoolchildren should justify the order of stages, choice of material, shape and dimensions of the workpiece, the manufacturing process, the necessary equipment, the possibility of decorating products, if it is needed to perform a sketch by hand with dimensioning.

Assessment of implementation of creative tasks is shown in Table 3.

Table 3

Assessment of Implementation of Creative Tasks

\begin{tabular}{ll}
\hline Task & Point \\
\hline 1. Proposed manufacturing; & 2 points \\
2. Sketch by hand with dimensions; & 2 points \\
3. Justification of the choice of material, shape, and dimensions of the workpiece; & 1 point \\
4. Justification of the choice of manufacturing techniques; & 2 points \\
5. Justification of the choice of equipment and tools needed; & 2 points \\
6. Possible decoration products (carving, painting, etc.). & 1 point \\
\hline
\end{tabular}

Possible one-detailed products for nomination "Technics and Technical Creativity" are: chopping board, chess pawn or castle, pointer, and tolkushka.

Schoolchildren are given one hour to complete the task. 
For a creative task, a pupil can get 10 points, all in all for tests and creative task: 35 points.

This task, being rather challenging, can reveal technological development of schoolchildren.

Next, in the second round, schoolchildren are required to complete a practical task with construction of a certain selected product in the category "Technics and Technical Creativity" by choice: hand or machine woodworking, hand or machine metalworking, electrical engineering, perhaps introduction of practical work on robotics. The assessment of practical work does not exceed 40 points.

Practical activities and practical incarnation of the project play the most important role in the programme of "Technology" in Russian schools. In techology education, $70 \%$ of all time is based on practice.

As an example, a practical task of the regional stage in electrical engineering XVI All-Russian Olympiad 2015 Technology of 10-11 grades will be provided (see Table 4). From the output of the bridge rectifier, voltage is applied to two parallel-connected incandescent lamps, to which a capacitive smoothing filter can be connected to. At the entrance of the bridge rectifier, elements of control and protection are connected.

Table 4

Example of a Practical Task

\begin{tabular}{lr}
\hline Task & Point \\
\hline 1. Draw a schematic diagram of the circuit; & 10 points \\
2. Measure the DC voltage on the lamps; & 5 points \\
3. Remove one lamp and measure the DC voltage on another lamp; & 5 points \\
$\begin{array}{l}\text { 4. Connect the smoothing filter and measure the constant the voltage across the two lamps; } \\
\text { 5. Observe with an oscilloscope and draw the shape of the voltage across the two lamps, without } \\
\text { the smoothing filter, then with a smoothing filter and on a lamp off after another. }\end{array}$ & 10 points \\
\hline
\end{tabular}

The students are given 180 minutes to do this task, including two 10-minute breaks.

The third round of each stage of the All-Russian Olympiad for schoolchildren on technology is connected with presentation of a creative project made by schoolchildren.

The following assessment criteria (see Table 5) of creative projects were used in the nomination "Technics and Technical Creativity".

Table 5

Assessment Criteria of Creative Projects (Up to 50 Points)

\begin{tabular}{|c|c|}
\hline \multirow{14}{*}{$\begin{array}{l}\text { Assessment of the } \\
\text { explanatory note of the } \\
\text { project (up to } 10 \text { points) }\end{array}$} & 1. General design; \\
\hline & 2. Relevance; formulating the problem and the project theme; \\
\hline & 3. Collecting information on the project; \\
\hline & 4. Analysis of prototypes; \\
\hline & 5. Analysis of possible ideas; selection of the optimal idea; \\
\hline & 6. Selection of manufacturing technology products; \\
\hline & 7. Interdisciplinary communication. Information from other subject areas for the project; \\
\hline & 8. Economic and environmental assessment of future product and technology of its manufacturing; \\
\hline & 9. Development of design documentation, the quality of graphics; \\
\hline & 10. Description of manufacturing; \\
\hline & 11. Description the final version of the product; \\
\hline & 12. Aesthetic assessment of the selected variant; \\
\hline & 13. Economic and environmental assessment of the finished product; \\
\hline & 14. Advertisement of the product. \\
\hline
\end{tabular}


(Table 5 to be continued)

\begin{tabular}{|c|c|}
\hline \multirow{4}{*}{$\begin{array}{l}\text { Product assessment } \\
\text { (up to } 25 \text { points) }\end{array}$} & 1. The originality of design; \\
\hline & 2. The quality of product; \\
\hline & 3. Compliance of the product's design with the theme; \\
\hline & 4. Practical significance. \\
\hline \multirow{9}{*}{$\begin{array}{l}\text { Assessment of presentation of } \\
\text { the project (up to } 15 \text { points) }\end{array}$} & 1. Formulating the problem and theme of the project; \\
\hline & 2. Analysis of prototypes and studies of the selected ideas; \\
\hline & 3. Description of technology of product's manufacturing; \\
\hline & 4. Interdisciplinary communication; \\
\hline & 5. Clarity; \\
\hline & 6. The depth of knowledge and erudition; \\
\hline & 7. Time of presentation; \\
\hline & 8. Self-assessment; \\
\hline & 9. Answers to the questions. \\
\hline
\end{tabular}

All in all, the participants can get up to 125 points. Duration of the first round (taking into account the description of process of preparation of the set product) is 1.5-2 astronomical hours. The second round - practical work, that is construction of a product-3 astronomical hours with two 10-minute breaks. In the third round, each pupil is given 10 minutes for presentation of his/her project.

\section{Results and Conclusion}

Here are some examples representing themes of the projects (nomination "Technics and Technical Creativity"), which got the best marks at the final stage of the Olympiad of 2014: (a) projects of the 9th grade pupils: "A Universal Rack", "A Bus-Stop of Near Future", "Tricycle", "A Casket to Enjoy", and "Panel-Triptych "Bashkir Motifs"; and (b) projects of the 10-11th grade pupils: "An Electronic Microscope for Education and Research", "Machine for Utilizing Plastic Waste", and "Thunderstorm Detector With Function of Disconnecting Household Appliances From the Power Supply Network" (Khotuntsev, Glozman, \& Nikonov, 2014).

These are the most interesting and creative projects from the final stage of the All-Russian Olympiad for schoolchildren on technology in 2015: (a) projects of the 9th grade: "Mechanical Manipulator", "Universal Tool Grinder", and "Radiodirected Model of a Sea Yacht"; and (b) projects of the 10th-11th grade: "Electronic Modernization of Door Lock", "The Lathe for a Turist of Metal", and "Smart Home".

About half of of the participants (45\%) of the final stage of the All-Russian Olympiad became winners and prizemen. Experience from the realization of the All-Russian Olympiad on technology showed that this is as an effective form to identify and encourage talented pupils.

\section{References}

Glozman, E. S., \& Khotuntsev, Y. L., Glozman, A. E., \& Stavrova, O. B. (2013a). Thechnology: Industrial Technology (Textbook for 5th grade). Moscow: Mnemonica. (In Russian)

Glozman, E. S., Khotuntsev, Yu. L., Glozman, A. E., \& Stavrova, O. B. (2013b). Thechnology: Industrial Technology (Textbook for 6th grade). Moscow: Mnemonica. (In Russian)

Glozman, E. S., Khotuntsev, Y. L., Glozman, A. E., \& Stavrova, O. B. (2014). Thechnology: Industrial Technology (Textbook for 7th grade). Moscow: Mnemonica. (In Russian)

Khotuntsev, Y. L. (2005). All-Russia Olympiad for schoolchildren on technology: Nomination "Technics and Thechnical Creativity”. Moscow: Academy. (In Russian) 
Khotuntsev, Y. L. (2006). All-Russia Olympiad for schoolchildren on technology: Nomination "Technics and Thechnical Creativity". Moscow: Academy. (In Russian)

Khotuntsev, Y. L., Glozman, E. S., Bakhteeva, L. A., \& Sarhze, A. V. (2011). “Technology” program on 5-11 grades. Moscow: Mnemonica. (In Russian)

Khotuntsev, Y. L., \& Glozman, E. S. (2014). Tasks of XV All-Russia Olympiad for schoolchildren on technology (Nomination "Technics and Thechnical Creativity" ). Journal of School and Production, 6, 16-30. (In Russian)

Khotuntsev, Y. L., Glozman, E. S., \& Nikonov, M. V. (2014). Rusults of XV All-Russia Olympiad for schoolchildren on technology (Nomination "Technics and Thechnical Creativity"). Journal of School and Production, 6, 3-6. (In Russian) 